\title{
The effect of overlearning on rate of extinction of the eyelid CR'
}

\author{
Kenneth W. Spence and E. F. Rutledge \\ STATE UNIVERSITY OF IOWA
}

\begin{abstract}
Human Ss were given either 50 or 150 eyelid conditioning trials in the context of a probability learning task. No difference was found in the subsequent extinction rate of the two groups. This finding contrasts sharply with the effects of similar overlearning on the rate of extinction of the instrumental runway responses. The results are interpreted as further evidence that the bases of inhibition are different in aversive and appetitionally motivated learning.
\end{abstract}

\section{Introduction}

Recent studies of extinction of the instrumental runing response (cf. Ison, 1962) have shown that with extended original training there occurs a decrement in the subsequent rate of extinction of the response. In terms of frustration theory (Amsel, 1958) this finding has been interpreted as indicating an increase in the strength of the anticipatory goal response $\left(r_{g}\right)$ and hence a stronger frustration response $\left(r_{f}\right)$ with its disruptive consequences when extinction is begun.

Evidence as to the effect of such overtraining on the extinction of classical aversive CRs is nonexistent. Studies of the human eyelid response have revealed that the number of CRs elicited in the extinction period have tended to increase as a function of the number of acquisition trials (Kimble \& Dufort, 1956; Prokasy, 1958; Spence, Rutledge \& Talbott, 1963). Such a finding, of course, merely reflects the different levels of response strength of the groups at the end of acquisition. Unfortunately, none of the studies report data on the rate of extinction as distinguished from the number of responses in extinction. A recent unpublished study (Rutledge, 1963) that employed a more extended range of $N$ values $(10,30$, $50,80,120$ ) found that the rate of approach of the different groups to their final asymptotic extinction level did not differ significantly. The number of Ss (18) in each group, however, makes acceptance of no decrement in extinction rate with extended training (120 trials) somewhat risky. The present study represents an attempt to provide more substantial data with regard to the effect of extended training on the rate of extinction of the conditioned eyelid response in human Ss. It employed $30 \mathrm{Ss}$ at an intermediate acquisition level of 50 trials and $30 \mathrm{Ss}$ at 150 trials.

\section{Method}

Each group (16 men and 14 women) was conditioned in the Iowa eyelid response set up. Six additional Ss were eliminated because they failed to reach an acquisition criterion of at least five CRs in the first 50 trials. The conditioning trials were embedded in a probability learn-

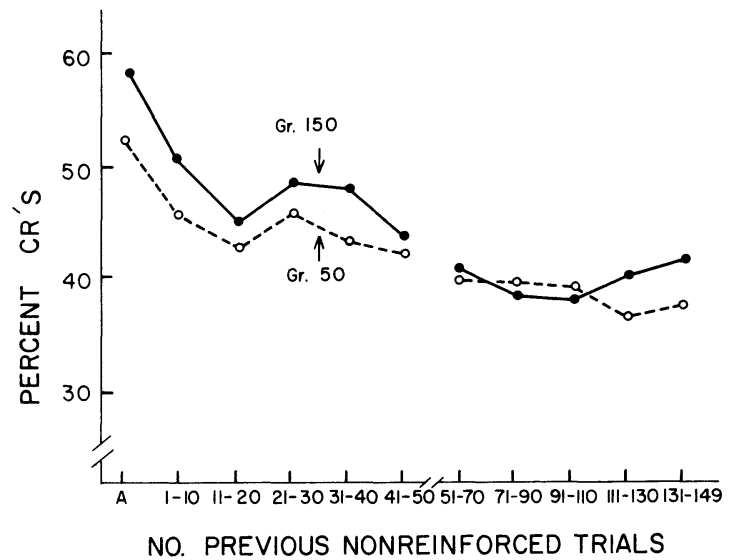

Fig. 1. Percentage of CRs during extinction as a function of number of previous nonreinforced trials.

ing or guessing game situation as described by Spence, Homzie \& Rutledge (1964). This masking situation involved a centrally placed light, the onset of which was a signal for $\mathrm{S}$ to anticipate which of two small light bulbs to the left and right of the signal light would light up. The Ss were instructed that the experiment was concerned with the effects of distraction on performance in a difficult problem solving task involving learning to predict which of the two lights would come on. They were further informed that distracting stimuli in the form of an air puff to their eye and a tone would be given in between their prediction response and onset of one of the lamps. The latter lighted up according to a prearranged schedule, seven times on one side and three times on the other. The CS, a 70-db, 500-cps tone, had a duration of 2550 msec. The UCS, a 1-psi air puff of $50 \mathrm{msec}$. duration, occurred $500 \mathrm{msec}$. after the onset of the CS. A photoelectric film programmer predetermined intertrial intervals of 9,12 , and $15 \mathrm{sec}$. Extinction involved a shift of the CS-UCS interval from 500 to 2500 msecs. In both acquisition and extinction a $C R$ was recorded whenever the pen gave a deflection of $1 \mathrm{~min}$. or more in the period 150-500 msec. following the onset of the CS.

\section{Results}

Examination of the acquisition data revealed that the 150 trial group attained asymptotic level at about 80 trials. As shown at point A on the abscissa of Fig. 1, this group averaged $58.2 \%$ CRs over the last 20 acquisi- 
tion trials (131-150). In its last 10 acquisition trials (41-50) the 50 trial group averaged $52.3 \%$ CRs, which is approximately $90 \%$ of the final level of the 150 trial group. Looking at the extinction curves in Fig. 1, it is apparent that Group 150 gave somewhat more CRs (63.4\% vs. $60.4 \%$ during extinction than Group 50. However, the difference was not significant $(t<1)$. Moreover, as the curves indicate, the rate of approach of the two groups to their final performance levels did not differ noticeably. Using the second of the statistical tests employing the shape function method proposed by Anderson $\left(1963\right.$, p. 167) the distributions of the $\mathrm{N}_{\mathrm{K}}$ values calculated for the two groups were found by the MannWhitney $U$ Test not to differ significantly $(p=.40)$.

A finding of some interest is the fact that the extinction curves of both groups appear to have reached an asymptote $(40 \%)$ considerably above the level of 10 to $20 \%$ response that has typically been obtained with the procedure of delaying the UCS in the standard situation (i.e., without the masking task). Goldstein (1962) and Rutledge (1963) obtained the same phenomenon. Analysis of the present data revealed that the higher final level resulted from the failure of about $30 \%$ of the Ss to show any decrease in their level of respondingduring the extinction period. This contrasts with the standard situation in which all Ss showed a significant decrease in response frequency in 100 extinction trials (Goldstein, 1962).

\section{Diseussion}

The results indicate that extending the training of the classical eyelid aversive CR 70 trials beyond the point at which asymptotic acquisition performance is attained led to no indication of a decrement in the rate with which the response extinguished. This finding contrasts with the effects of similar amounts of overtraining in the runway situation. As has been pointed out by the senior author (Spence, 1960, p.110) the findings with respect to the effects of partial nonreinforcement on performance during acquisition in these two learning situations have also been opposite in nature. The interpretation given there was that the mechanisms of inhibition in the two situations are probably quite different. There is pre- sumably no frustration operating in the classical aversive response as there is in the appetitively motivated instrumental running response.

\section{References}

AMSEL, A. The role of frustrative nonreward in noncontinuous reward situation. Psychol. Bull., 1958, 55, 102-119.

ANDERSON, N. H. Comparison of different populations: resistance to extinction and transfer. Psychol. Rev., $1963,70,162-179$.

GOLDSTEIN, H. The effects of set factors and reinforcement schedules on the acquisition and extinction of the conditioned eyelid response. Unpublished Ph.D. dissertation, State University of Iowa, 1962.

ISON, J. R. Experimental extinction as a function of reinforcement. J.exp. Psychol., 1962, 64, 314-317.

KIMBLE, G. A., \& DUFORT, R. H. The associative factor in eyelid conditioning. J.exp. Psychol., 1956, 52, 386-391.

PROKASY, W. F. Extinction and spontaneous recovery of conditioned eyelid responses as a function of amount of acquisition and extinction training. J.exp. Psychol., 1958, 56, 319-324.

RUTLEDGE, EDWARD F. Extinction of the conditioned eyelid response as a function of number of reinforcements. Unpublished Ph.D. dissertation, State University of Iowa, 1963.

SPENCE, K. W. Behavior Theory and Learning. Englewood Cliffs, New Jersey: Prentice-Hall, 1960.

SPENCE, K. W., RUTLEDGE, E. F., \& TALBOTT, J. Effect of the number of acquisition trials and the presence of the UCS on extinction of the human eyelid CR. J. exp. Psychol., 1963, 66, 286-291.

SPENCE, K. W., HOMZIE, M. J., \& RUTLEDGE, E. F. Extinction of the human eyelid $\mathrm{CR}$ as a function of the discriminability of the change from acquisition to extinction. J. exp. Psychol., 1964, 67, 545-552.

\section{Note}

1. This study was carried out as part of a project concerned with classical conditioning in humans under Contract Nonr-1509(04) between the University of Iowa and the Office of Naval Research. 